\title{
Cerebral Blood Flow during Spontaneous and Cholinergically Induced Behavioral States in the Sheep Fetus
}

\author{
JANNA L. MORRISON, LESLEY CARMICHAEL, JACOBUS HOMAN, SUSAN WHITE, AND \\ BRYAN S. RICHARDSON \\ CIHR Group in Fetal and Neonatal Health and Development, University of Western Ontario, Lawson \\ Health Research Institute, St. Joseph's Health Centre, London, Ontario, N6A 4V2, Canada
} \begin{abstract}
ABST
The sleep-wake cycle has been studied extensively in both
adult and fetal mammalian species with emphasis in different areas. Fetal studies have focused on characterization of behavioral states and responses to challenges such as hypoxia, and there have been relatively fewer studies that have investigated the control of fetal behavioral state. The objective of this study was to determine whether cerebral blood flow during cholinergically induced fetal behavioral states was similar to that during spontaneous fetal behavioral states in chronically catheterized near-term sheep fetuses. Injection of carbachol $(1.25 \mu \mathrm{g})$ into the cisterna magna increased the duration of the subsequent lowvoltage electrocortical epoch. Scopolamine infusion $(0.3 \mathrm{mg})$ increased the duration of the subsequent high-voltage electrocortical activity epoch. Cerebral blood flow and oxygen delivery were higher during both spontaneous and carbachol-induced low-voltage/rapid eye movement behavioral state than during spontaneous and scopolamine-induced high-voltage/non-rapid
\end{abstract}

eye movement behavioral state. Thus, pharmacologic manipulation of fetal behavioral state induced a state that resembled spontaneous fetal behavioral state both electrophysiologically and metabolically. This study shows that inducing extended periods of a desired fetal behavioral state is possible and that this method may be used to study their function. (Pediatr Res 57: 667-673, 2005)

CBF, cerebral blood flow

Abbreviations

CMR, cerebral metabolic rate

EMG, electromyograph

FBM, fetal breathing movements

HV, high-voltage

LV, low-voltage

NREM, non-rapid eye movement

REM, rapid eye movement
Cycles of behavioral state are present before birth in species in which significant brain development occurs in utero, including the rhesus monkey, guinea pig, and sheep. After $120 \mathrm{~d}$ gestation (term $=145 \pm 3 \mathrm{~d})$, the sheep fetus cycles between a low-voltage (LV)/rapid eye movement (REM) behavioral state-characterized by LV fast electrocortical activity, rapid eye movements, and nuchal muscle atonia — and a high-voltage $(\mathrm{HV}) /$ non-rapid eye movement (NREM) behavioral statecharacterized by HV slow electrocortical activity, no eye movements, and nuchal muscle tone (1) every 30-40 min (2). Near term, after $135 \mathrm{~d}$, the sheep fetus exhibits short periods of "wakefulness" as defined by LV fast electrocortical activity and nuchal muscle tone $(3,4)$. In addition, cerebral metabolic rate (CMR) of oxygen and cerebral blood flow (CBF) are

Received October 27, 2003; accepted September 3, 2004.

Correspondence: Janna Morrison, Ph.D., Medical School South, Room S515, Discipline of Physiology, School of Molecular and Biomedical Sciences, Adelaide University, Adelaide, SA, Australia, 5005; e-mail: janna.morrison@adelaide.edu.au.

This work was supported by a grant from the Canadian Institutes of Health Research.

DOI: 10.1203/01.PDR.0000156210.27381.12 increased during LV/REM compared with HV/NREM behavioral state (5). These fetal behavioral states are electrophysiologically similar to the REM and NREM sleep states observed during adult sleep, and higher CBF has been measured during REM sleep compared with NREM sleep in all adult mammals studied (6-8).

Cholinergic drugs also alter REM and NREM sleep in adult species. Microinjection of carbachol into brainstem nuclei of the pontine reticular formation increases REM episodes in rats (9). Likewise, rats that are treated with s.c. infusion of scopolamine exhibit a decrease in sleep, with greater suppression of REM than NREM sleep (10). In the sheep fetus, a 90-min infusion of carbachol increases the incidence of LV/REM behavioral state $(11,12)$, whereas scopolamine administration increases the incidence of HV/NREM behavioral state (12). Evidence also exists for the cholinergic system's role in the regulation of $\mathrm{CBF}$ in adults. Cholinergic neurons in the basal forebrain play a role in the regulation of CMR (13), and injection of the cholinergic agonist carbachol into the substantia innominata increases CBF in rats. This effect can be blocked 
in some cortical regions by systemic treatment with scopolamine, a cholinergic antagonist (14). To date, no studies have determined whether the cholinergically induced changes in fetal behavioral state are accompanied by changes in CBF normally observed between behavioral states. The purpose of this study therefore was to 1 ) determine the effects of bolus infusion of carbachol and scopolamine administered into the fetal cisterna magna on fetal behavioral state and 2) determine whether the subregional pattern of $\mathrm{CBF}$ and oxygen delivery during the cholinergically induced behavioral states were different from those measured during spontaneous fetal behavioral states.

\section{METHODS}

All procedures and protocols were performed with the approval of the University of Western Ontario Animal Care Committee and in accordance with the Canadian Council on Animal Care guidelines. Animals were housed in individual cages, which allowed for continuous monitoring of fetal physiologic parameters and maternal health, with food and water available ad libitum.

Surgical procedures. Fourteen pregnant sheep of mixed breed were surgically prepared at a gestational age of $127 \mathrm{~d}$ (term, $145 \mathrm{~d}$ ) as previously described (15). Anesthesia was induced with a $40-\mathrm{mL}$ injection of pentothal into the maternal jugular vein and maintained with $1.0-1.5 \%$ halothane and oxygen. The uterus was exposed and opened through a midline incision in the lower abdomen. Polyvinyl catheters (Bolab, Lake Havasu City, AZ) were placed into the fetal inferior vena cava via the pedal vein for antibiotic and radioactive labeled microsphere infusion, the brachiocephalic artery for blood sampling and pressure measurement, and the trachea and amniotic cavity for pressure measurement. Electrodes of Teflon-coated stainless steel wire (Cooner, Chatsworth, CA) were implanted biparietally on the dura for fetal electrocortical activity recordings, through the lateral orbital ridge of the zygomatic bone of each eye for measurement of eye movements, and in the nuchal muscle for electromuscular [electromyograph (EMG)] recordings. A reference electrode was sutured into the loose connective tissue over the occipital bone of the skull. A drug infusion catheter was implanted in the cisterna magna as previously described (Bolab V4) $(12,16,17)$. The catheters, which contained heparinized saline, and electrodes were exteriorized through the flank of the ewe, and the abdomen was closed in layers. A polyvinyl catheter was placed in the maternal femoral vein for blood sampling. Animals were allowed $3 \mathrm{~d}$ of recovery from surgery during which the fetuses were administered $1 \mathrm{~mL}$ of penicillin $\mathrm{G}$ sodium 10 million $\mathrm{IU} / \mathrm{mL}$ to both the amniotic cavity and the fetal vein, and the ewes received an i.m. injection of $4 \mathrm{~mL}$ of Pendistrep (penicillin G procaine 200,000 IU/mL and dihydrostreptomycin base of $250 \mathrm{mg} / \mathrm{mL}$ ) daily.

Physiologic recordings. Fetal behavioral state parameters were monitored continuously throughout the experimental periods. Tracheal, amniotic cavity, and brachiocephalic arterial pressures were recorded using strain gauge manometers (Model P-23 ID; Canadian Cardiovascular Products, Mississauga, ON, Canada) and a strip chart recorder (Model 78D; Astro-Med, Grass Division, Boucherville, PQ, Canada). Mean arterial blood pressure was referenced to amniotic fluid pressure and calculated as the sum of diastolic and 0.4 of pulse pressure. Electrical signals were processed by means of a common mode rejection preamplifier (Model 7P 511J). Fetal electrocortical activity, eye movements, and EMG potentials were displayed directly on the strip chart recorder after passing through a passive band-pass filter, $0.3-30 \mathrm{~Hz}$ for electrocortical activity and eye movements and $0.3-60 \mathrm{~Hz}$ for nuchal EMG, on the preamplifier. The electrocortical activity signal was additionally processed through a bandpass filter of $3-10 \mathrm{~Hz}$, and the frequency shift then was displayed on the strip chart recorder. Fetal blood samples were analyzed for oxygen saturation and $\mathrm{Hb}$ using an OSM2 hemoximeter (Radiometer, Copenhagen, Denmark), and blood gases and $\mathrm{pH}$ were analyzed using an ABL-500 blood gas analyzer (Radiometer) with temperature corrected to $39.5^{\circ} \mathrm{C}$. Oxygen content then was calculated using an oxygen capacity of $1.36 \mathrm{~mL} / \mathrm{g} \mathrm{Hb}$ (4).

Experimental protocols. Experiments extended over $2 \mathrm{~d}$ with a 2-h control period each day followed by a 1-mL bolus injection of either carbachol (1.25 $\mu \mathrm{g})$ or scopolamine $(0.3 \mathrm{mg})$ dissolved in Ringer's solution into the fetal cisterna magna over 1 min followed by a 1-mL flush with lactated Ringer's solution over $1 \mathrm{~min}$ and then a 4-h recovery period. Regional CBF measurements were performed each day during a spontaneous (control period) and a drug-induced fetal behavioral state by injecting $\sim 1.5 \times 10^{6}$ (range 1.2-2.5 $\times$ $\left.10^{6}\right), 15-\mu \mathrm{m}$ diameter radioactive labeled $\left({ }^{141} \mathrm{Ce},{ }^{51} \mathrm{Cr},{ }^{85} \mathrm{Sr}\right.$, or $\left.{ }^{46} \mathrm{Sc}\right)$ micro- spheres (New England Nuclear, Boston, MA) into the fetal inferior vena cava. A reference sample was obtained by withdrawal from the brachiocephalic artery for $2 \mathrm{~min}$ at a rate of $2.06 \mathrm{~mL} / \mathrm{min}$ with a Harvard infusion-withdrawal pump $(4,5)$. The CBF measurement was made during LV/REM behavioral state in the control periods preceding the infusion of carbachol into the cisterna magna and during HV/NREM behavioral state in the control periods preceding the infusion of scopolamine. During the control period, CBF measurements began at least $3 \mathrm{~min}$ after a switch to the desired fetal behavioral state followed by a period in that behavioral state of at least $1 \mathrm{~min}$ to ensure that a change in fetal behavioral state was not only initiated but also maintained. Carbachol infusion was performed after $2 \mathrm{~min}$ of spontaneous HV/NREM activity, and scopolamine infusion occurred after 2 min of spontaneous LV/REM activity. The second blood flow measurement each day began after $5 \mathrm{~min}$ of the corresponding drug-induced behavioral activity (carbachol-induced LV/REM, scopolamine-induced HV/NREM) and followed by a minimum of $1 \mathrm{~min}$ in that state. Blood samples from the brachiocephalic artery were obtained immediately before and after each blood flow measurement. Approximately $5 \mathrm{~mL}$ of blood was withdrawn for each blood flow measurement and blood gas analysis. The order of administration of carbachol and scopolamine was randomized, and the protocol was repeated on the second day with the second drug.

On completion of the studies, the ewe and fetus were killed and an autopsy was performed on the fetus to validate placement of the fetal catheters. Cisterna magna catheter placement was visually confirmed during the autopsy before dissection, and the catheter was always positioned over the dorsal surface of the pons and medulla. The brain was weighed and dissected in the following manner: cerebral cortex (data for right and left lobes was averaged; frontal lobe, temporal lobe, parietal lobe, and occipital lobe), subcortex (thalami, hippocampi, colliculi, and corpus striatum), brainstem (midbrain reticular formation, substantia nigra/lateral geniculate body, brainstem reticular formation, pons, and medulla), and cerebellum (cerebellar hemisphere and vermis) (4). Previous studies show that for the number of microspheres that reach a brain region/subregion to be within $10 \%$ for concurrent measurements, a minimum of 400 microspheres must be in that portion of tissue $(18,19)$. Only the substantia nigra/lateral geniculate body in one animal did not satisfy this criterion. Tissues were weighed separately, and radioactivity was analyzed using a gamma counter (CompuGamma model 1282; LKB Wallac Oy, Turku, Finland). Blood flow (20) and oxygen delivery (21) to these tissue regions were then calculated.

Data analysis. Electrocortical activity was analyzed by visual inspection and divided into periods of $\mathrm{LV}(<50 \mu \mathrm{V})$, intermediate voltage $(50-100 \mu \mathrm{V})$, and HV (100-200 $\mu \mathrm{V})(15,22)$. Frequency shift data from the strip chart recordings were also used to confirm changes in electrocortical activity. Eye movement activity was deemed to be present when the episode lasted longer than $30 \mathrm{~s}$ with an amplitude $>50 \mu \mathrm{V}$. Repeated negative deflections in tracheal pressure $>2 \mathrm{~mm} \mathrm{Hg}$ for $>30 \mathrm{~s}$ were classified as fetal breathing movements (FBM) (22). EMG activity of the nuchal muscle was also analyzed by visual inspection and noted to be generally present or absent but was not quantified. Electrocortical activity, eye movement activity, and FBM are expressed as the percentage of time spent hourly during the control period $2 \mathrm{~h}$ before and recovery period $4 \mathrm{~h}$ after the bolus drug injection $(15,23)$. Fetal mean arterial blood pressure was calculated every $5 \mathrm{~min}$ and then averaged for each hour of the control and recovery period. Oxygen delivery to brain regions was calculated as the product of blood flow to that region and the mean of the arterial oxygen content sampled before and after that blood flow measurement. Not all metabolic and biophysical measurements or experiments were performed in each animal because of catheter failure, a switch in behavioral state at the time of microsphere injection, fetal death, and/or technical difficulties. Thus, the data presented for this study were obtained from six fetuses that successfully completed all four blood flow determinations. All metabolic and biophysical data were analyzed using two-way repeated measures ANOVA followed by Bonferroni post hoc $t$ tests (SigmaStat; SPSS, Chicago, IL). Data are presented as mean $\pm \mathrm{SEM}$.

\section{RESULTS}

Blood gas status. Fetal weight at autopsy averaged $3.7 \pm 0.4$ $\mathrm{kg}$ (range, $2.6-4.8 \mathrm{~kg}$ ). Fetal arterial blood gases, $\mathrm{pH}$, and $\mathrm{O}_{2}$ content were monitored at the time of each blood flow determination and were consistent with those previously measured in healthy fetuses of this gestational age (131-132 d) $(4,12)$. There were no differences in these measurements between the spontaneous and drug-induced behavioral states as measured at the time of microsphere injection (Table 1). There was an effect, however, of fetal behavioral state on arterial $\mathrm{pH}\left(\mathrm{F}_{1,5}=\right.$ 
Table 1. Arterial blood gas measurements

\begin{tabular}{lcccc}
\hline & $\begin{array}{c}\text { Spontaneous } \\
\text { LV/REM }\end{array}$ & $\begin{array}{c}\text { Carbachol-induced } \\
\text { LV/REM }\end{array}$ & $\begin{array}{c}\text { Spontaneous } \\
\text { HV/NREM }\end{array}$ & $\begin{array}{c}\text { Scopolamine-induced } \\
\text { HV/NREM }\end{array}$ \\
\hline $\mathrm{CaO}_{2}(\mathrm{mmol} / \mathrm{L})$ & $3.3 \pm 0.3$ & $3.0 \pm 0.2$ & $3.1 \pm 0.2$ & $3.0 \pm 0.2$ \\
$\mathrm{PaO}_{2}(\mathrm{~mm} \mathrm{Hg})$ & $23.6 \pm 1.8$ & $22.7 \pm 1.5$ & $21.9 \pm 1.8$ & $22.1 \pm 1.4$ \\
$\mathrm{PaCO}_{2}(\mathrm{~mm} \mathrm{Hg})$ & $46.6 \pm 2.9$ & $42.4 \pm 4.0$ & $47.0 \pm 1.9$ & $44.7 \pm 1.8$ \\
$\mathrm{pHa}$ & $7.35 \pm 0.02^{\mathrm{a}}$ & $7.34 \pm 0.01^{\mathrm{a}}$ & $7.37 \pm 0.01^{\mathrm{b}}$ & $7.36 \pm 0.01^{\mathrm{b}}$ \\
$\mathrm{Hb}(\mathrm{g} / 100 \mathrm{~mL})$ & $9.1 \pm 0.6$ & $8.4 \pm 0.5$ & $8.9 \pm 0.7$ & $8.9 \pm 0.6$ \\
\hline
\end{tabular}

Data are presented as means \pm SEM. Mean values with different alphabetic superscripts are different $(p<0.05)$. Significance based on paired data by two-way repeated measures ANOVA followed with paired $t$ tests using a Bonferroni correction and indicated by different letters. $\mathrm{CaO}_{2}, \mathrm{O}_{2} \mathrm{content}$ in arterial blood; PaO ${ }_{2}$, partial pressure of arterial $\mathrm{O}_{2} ; \mathrm{PaCO}_{2}$, partial pressure of arterial $\mathrm{CO}_{2}$.

11.28, $p=0.02$ ) such that $\mathrm{pH}$ was lower in LV/REM behavioral state than HV/NREM behavioral state whether spontaneous or drug induced (Table 1).

Fetal behavioral state. Bolus injection of carbachol did not significantly affect the percentage of time spent in LV electrocortical activity, eye movements, or FBM during the hour after the infusion $\left(\mathrm{F}_{1,5}<1.76, p>0.16\right.$; Fig. $\left.1 A\right)$. Eye movements and FBM were confined to periods of $\mathrm{LV}$ electrocortical activity. The duration of LV electrocortical activity epochs was significantly greater, however, after injection of carbachol $(20.3 \pm 6.8 \mathrm{~min})$ compared with the duration of spontaneously occurring LV electrocortical activity epochs $(12.3 \pm 2.4 \mathrm{~min}$; $\mathrm{F}_{1,5}=17.83, p=0.01$; Fig. $\left.2 A\right)$. Fetal mean arterial blood pressure was not altered by the bolus injection of carbachol (control, $51.3 \pm 3.4 \mathrm{~mm} \mathrm{Hg}$; carbachol, $53.3 \pm 3.1 \mathrm{~mm} \mathrm{Hg}$ ).

Administration of scopolamine resulted in a significant increase in the percentage of time spent in $\mathrm{HV}$ electrocortical
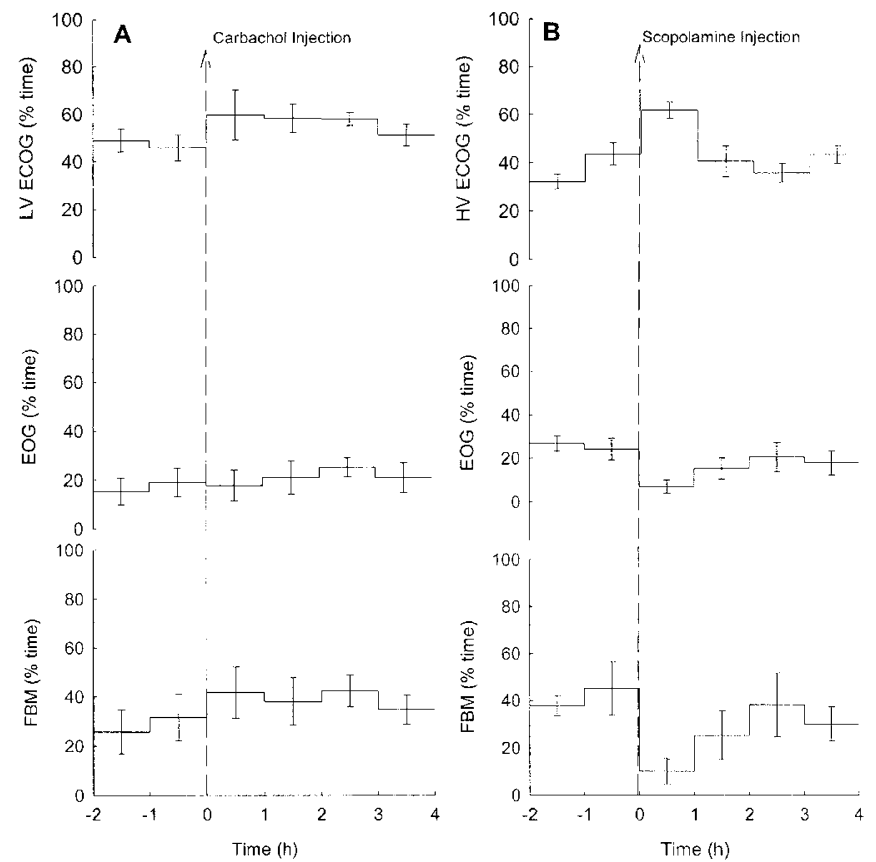

Figure 1. Percentage of time spent in LV electrocortical $(A)$ or HV electrocortical activity $(B)$, eye movements $(A$ and $B)$, and FBM $(A$ and $B)$ after bolus injection of carbachol $(A)$ or scopolamine $(B)$ into the cisterna magna of the sheep fetus at $130 \mathrm{~d}$ gestation (term, $147 \mathrm{~d}$ ). Carbachol injection had no effect on the incidence of LV electrocortical activity, eye movement, or FBM (A) whereas scopolamine injection significantly increased the incidence of HV electrocortical activity and decreased eye movements and FBM. ECOG, electrocortical activity; EOG, eye movements. activity in the hour after the infusion $\left(\mathrm{F}_{1,5}=6.50, p=0.01\right)$ and a concomitant decrease in the percentage of time spent in LV electrocortical activity (Fig. 1B). A significant decrease in the incidence of eye movement activity also occurred during the hour after infusion. The duration of the HV electrocortical activity epochs that occurred after scopolamine injection were significantly longer $(22.6 \pm 3.3 \mathrm{~min})$ than the duration of spontaneous $\mathrm{HV}$ electrocortical activity epochs (10.4 \pm 0.7 $\left.\min ; \mathrm{F}_{1,5}=17.83, p=0.01\right)$. In the 1 - $\mathrm{h}$ period after scopolamine, $29.2 \pm 18.7 \%$ (range, $0-100 \%$ ) of EOG activity occurred during $\mathrm{HV}$ electrocortical activity compared with no eye movements during this behavioral state before drug exposure $\left(\mathrm{F}_{1,5}=2.13, p=0.09\right.$; Fig. $\left.2 B\right)$. In addition, FBM were present during $\mathrm{HV}$ electrocortical activity in the hour after scopolamine infusion $\left(38.1 \pm 13.2 \%\right.$; range, 0 to $64.3 \% ; \mathrm{F}_{1,5}$ $=1.53, p=0.24$ ) in contrast to before drug exposure, when there was no FBM present during HV electrocortical activity (Fig. 2B). There was no difference in fetal mean arterial blood pressure after scopolamine (control, $46.5 \pm 2.0 \mathrm{~mm} \mathrm{Hg}$; scopolamine, $51.3 \pm 1.4 \mathrm{~mm} \mathrm{Hg}$ ).

$\boldsymbol{C B F}$. CBF to the whole brain seemed higher during spontaneous LV/REM than during spontaneous HV/NREM behavioral state (Fig. 3), although this difference was not significant, primarily as a result of variability in CBF in HV/NREM behavioral state. All spontaneous HV/NREM measures were made in the absence of eye movements and FBM. One measurement during scopolamine-induced HV/NREM behavioral state was made in the presence of FBM. CBF to the whole brain during carbachol-induced LV/REM behavioral state was not different compared with that measured during spontaneous LV/REM behavioral states. Similarly, CBF during scopolamine-induced HV/NREM behavioral states was not different from that in spontaneous HV/NREM behavioral states. CBF to the brain seemed higher during carbachol-induced LV/REM behavioral state $\left(220 \pm 24 \mathrm{~mL} \cdot \mathrm{min}^{-1} \cdot 100 \mathrm{~g}^{-1}\right)$ compared with scopolamine-induced HV/NREM behavioral state (156 \pm $\left.16 \mathrm{~mL} \cdot \min ^{-1} \cdot 100 \mathrm{~g}^{-1}\right)$, although this was not significant $\left(\mathrm{F}_{1,5}=3.71, p=0.11\right)$.

Regional blood flows within the brain were higher during LV/REM behavioral state than during HV/NREM behavioral state for the subcortex $\left(\mathrm{F}_{1,5}=12.54, p=0.02\right)$ and brainstem $\left(\mathrm{F}_{1,5}=14.69, p=0.01\right)$ whether the behavioral state was drug induced or spontaneous. Blood flow to the cerebellum maintained this state-dependent pattern; however, drug treatment had an additional effect such that flow was greater during carbachol compared with spontaneous LV/REM behavioral 
A

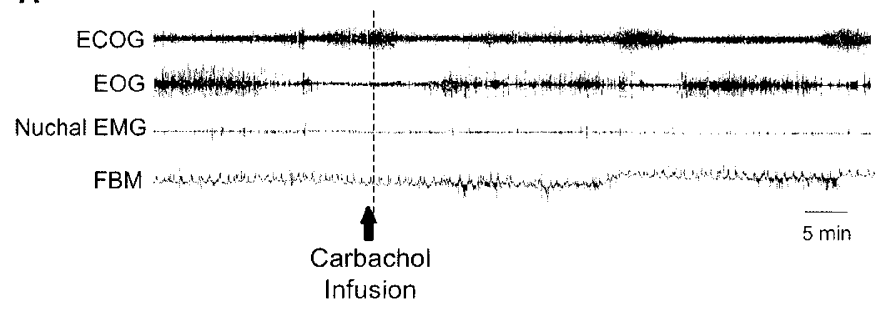

B

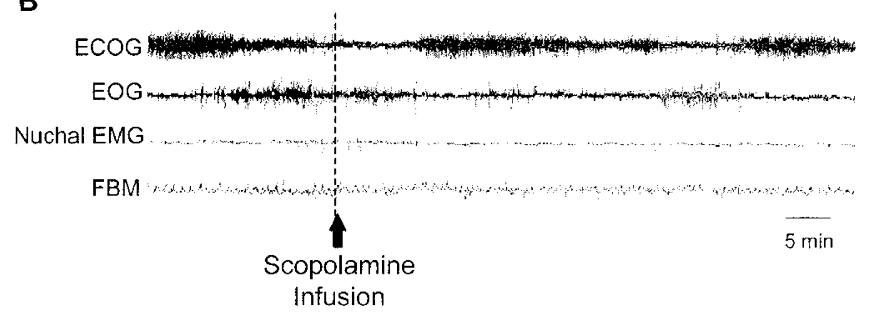

Figure 2. Strip chart recording illustrating the effect of bolus carbachol infusion $(1.25 \mu \mathrm{g} ; A)$ or scopolamine $(0.3 \mathrm{mg} ; B)$ into the cisterna magna of a $130-\mathrm{d}$ sheep fetus. A prolonged LV/REM behavioral state is exhibited with the confinement of eye movements and FBM to LV electrocortical activity after carbachol injection $(A)$. An increase in HV electrocortical activity was observed after bolus scopolamine injection, with eye movements and FBM activity occurring during epochs of HV electrocortical activity $(B)$.

state and lower in scopolamine compared with spontaneous HV/NREM behavioral state, and this interaction between drug and state was significant $\left(\mathrm{F}_{1,5}=11.99, p=0.02\right)$.

Blood flow to the subregions of the brain was also higher during spontaneous LV/REM than HV/NREM behavioral state. The exceptions were the cerebellar hemisphere and vermis, where the effect of drug was dependent on state $\left(\mathrm{F}_{1,5}>\right.$ $10.59, p<0.02)$.

Oxygen delivery. Oxygen delivery to the whole brain was not different between spontaneous LV/REM and HV/NREM

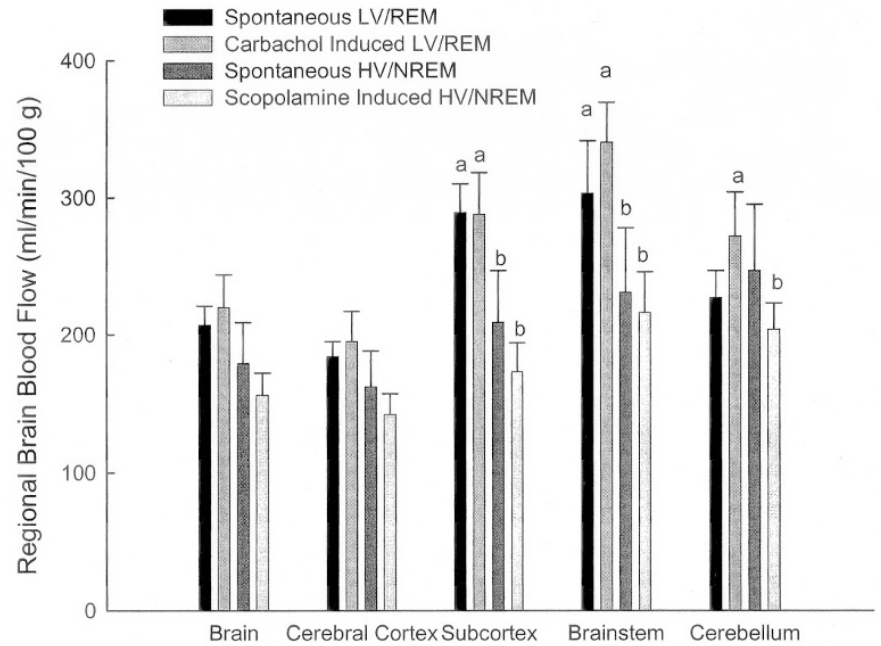

Figure 3. Blood flow to the brain and its major regions during spontaneous and drug-induced behavioral states in the sheep fetus. Data are presented as means \pm SEM. Mean CBF values with different alphabetic superscripts are significantly different $(p<0.05)$. Significance based on paired data by two-way repeated measures ANOVA followed with paired $t$ tests using a Bonferroni correction and indicated by different letters.

behavioral states (Table 2). There was no effect of either carbachol or scopolamine on oxygen delivery to the brain as a whole. Oxygen delivery to the major regions and subregions within the brain, however, was higher during spontaneous LV/REM than during spontaneous HV/NREM behavioral state for the subcortex $\left(\mathrm{F}_{1.5}=9.47, p=0.03\right)$ and the brainstem $\left(\mathrm{F}_{1,5}=12.67, p=0.02\right.$; Table 2$)$. There was no additional effect of either carbachol or scopolamine on oxygen delivery to the brain regions or subregions. Thus, changes in oxygen delivery to brain subregions that occurred after drug injection

Table 2. Oxygen delivery $\left(\mu \mathrm{mol} \cdot \mathrm{min}^{-1} 100 \mathrm{~g}^{-1}\right)$ : spontaneous and drug-induced state-related changes

\begin{tabular}{|c|c|c|c|c|}
\hline & $\begin{array}{l}\text { Spontaneous } \\
\text { LV/REM }\end{array}$ & $\begin{array}{c}\text { Carbachol-induced } \\
\text { LV/REM }\end{array}$ & $\begin{array}{l}\text { Spontaneous } \\
\text { HV/NREM }\end{array}$ & $\begin{array}{c}\text { Scopolamine-induced } \\
\text { HV/NREM }\end{array}$ \\
\hline Total brain & $656 \pm 49$ & $611 \pm 62$ & $589 \pm 96$ & $532 \pm 52$ \\
\hline Cerebral cortex & $587 \pm 46$ & $537 \pm 55$ & $533 \pm 83$ & $484 \pm 44$ \\
\hline Temporal lobe & $557 \pm 50$ & $522 \pm 58$ & $502 \pm 78$ & $451 \pm 44$ \\
\hline Parietal lobe & $597 \pm 49$ & $558 \pm 51$ & $552 \pm 93$ & $522 \pm 55$ \\
\hline Occipital lobe & $607 \pm 55$ & $580 \pm 64$ & $531 \pm 69$ & $478 \pm 60$ \\
\hline Thalamus & $1012 \pm 100^{\mathrm{a}}$ & $886 \pm 110^{\mathrm{a}}$ & $736 \pm 149^{\mathrm{b}}$ & $641 \pm 92^{b}$ \\
\hline Colliculi & $1137 \pm 122^{\mathrm{a}}$ & $1047 \pm 123^{a}$ & $939 \pm 189^{\mathrm{b}}$ & $768 \pm 115^{\mathrm{b}}$ \\
\hline Hippocampus & $668 \pm 71^{\mathrm{a}}$ & $634 \pm 100^{\mathrm{a}}$ & $477 \pm 53^{\mathrm{b}}$ & $424 \pm 37^{\mathrm{b}}$ \\
\hline Brainstem & $951 \pm 93^{\mathrm{a}}$ & $985 \pm 107^{\mathrm{a}}$ & $754 \pm 144^{\mathrm{b}}$ & $705 \pm 100^{\mathrm{b}}$ \\
\hline Midbrain RF & $1047 \pm 126^{\mathrm{a}}$ & $996 \pm 135^{\mathrm{a}}$ & $745 \pm 156^{\mathrm{b}}$ & $642 \pm 101^{\mathrm{b}}$ \\
\hline SN/LGB & $763 \pm 63^{\mathrm{a}}$ & $822 \pm 115^{\mathrm{a}}$ & $574 \pm 111^{\mathrm{b}}$ & $497 \pm 125^{\mathrm{b}}$ \\
\hline Hemisphere & $676 \pm 50$ & $682 \pm 70$ & $716 \pm 119$ & $641 \pm 65$ \\
\hline Vermis & $751 \pm 62$ & $817 \pm 90$ & $901 \pm 171$ & $777 \pm 76$ \\
\hline
\end{tabular}

Data are presented as means \pm SEM. Mean oxygen delivery values with different alphabetic superscripts are significantly different $(p<0.05)$. Significance based on paired data by two-way repeated measures ANOVA followed with paired $t$ tests using a Bonferroni correction and indicated by different letters. SN/LGB, substantia nigra/lateral geniculate body; RF, reticular formation. 
were no different from those observed during spontaneously behavioral state cycling.

\section{DISCUSSION}

The present study shows that cholinergic agents administered via bolus injection rather than infusion into the cisterna magna of the late-gestation sheep fetus transiently alters electrophysiologically defined fetal behavioral states. Electrophysiologic change is accompanied by a metabolic change that is similar to that observed during spontaneous fetal behavioral states, whereby CBF has a tendency to be higher during LV/REM than HV/NREM behavioral state to most brain regions. In addition, oxygen delivery was higher to the subcortex and brainstem in LV/REM behavioral state compared with HV/NREM behavioral state whether these were spontaneous or cholinergically induced behavioral states.

Previous studies have found no significant differences in arterial oxygen pressure and $\mathrm{pH}$ between LV/REM and HV/ NREM fetal behavioral state $(4,24,25)$. Small differences in arterial partial pressure of carbon dioxide have been observed between fetal behavioral states that have been either significant (4) or not significant (25). In addition, there is an effect of FBM on blood gas and $\mathrm{pH}$ such that as the amplitude and the duration of FBM increase, there is a fall in arterial oxygen pressure and $\mathrm{pH}$ with a rise in arterial partial pressure of carbon dioxide (26). In the present study, $\mathrm{pH}$ is lower during both spontaneous and carbachol-induced LV/REM behavioral state; however, these values are within the normal range (27). As previously shown (11), pH fell slightly after carbachol injection with no changes in blood gas status $(11,28)$. In addition, a 90 min infusion of scopolamine into the cisterna magna had no effect on fetal blood gas or $\mathrm{pH}$ status (28).

Cholinomimetics that are known to alter adult sleep-wake states also alter fetal behavioral sleep states in sheep. The present study showed that a bolus carbachol infusion increased the duration of the subsequent LV/REM behavioral state epoch without significantly altering the hourly incidence of LV electrocortical activity, eye movements, or FBM activity. These findings support work by Bissonnette et al. (11), previous results reporting that a $1-\mu \mathrm{g}$ bolus infusion of carbachol resulted in a nonsignificant increase in LV electrocortical activity of 1.2-fold. Likewise, Bissonnette et al. (11) noted an increase in FBM and the occurrence of FBM during HV electrocortical activity. It is interesting that this study did not show an increase in FBM, and all FBM were confined to periods of LV electrocortical activity. These data raise the possibility that carbachol may induce arousal in the fetus as noted by the increase in $\mathrm{LV}$ electrocortical activity but not eye movements and independently increase FBM. We think it more likely that LV/REM behavioral state was induced as we have previously demonstrated that a 90-min perfusion of a high dose of carbachol $\left(1.35 \times 10^{-5} \mathrm{M}\right)$ to the cisterna magna increased the incidence of LV/REM behavioral state, whereas a lower dose $(4.5 \times$ $\left.10^{-6} \mathrm{M}\right)$ did not alter the incidence of LV/REM behavioral state (12). Similarly, scopolamine injection increased HV electrocortical activity and decreased LV electrocortical, eye movement, and FBM activity as previously shown with a 90-min perfusion of the cisterna magna (12). In this study, however, eye movements were observed during HV electrocortical activity. It seems that despite the effect of scopolamine to induce $\mathrm{HV}$ electrocortical activity and suppress eye movements, this might not be a true behavioral state as a result of a loss of the normal synchrony seen in the clustering of parameters (HV electrocortical activity, no eye movements, and no FBM) used to define HV/NREM behavioral state. Alternatively, scopolamine may act directly on centers that control eye movements and FBM.

Previous studies have shown that in adults, CBF is greater during REM sleep compared with NREM sleep (6). Similarly, $\mathrm{CBF}$ is greater during spontaneous LV/REM compared with spontaneous HV/NREM behavioral state in the sheep fetus $(4,5,29)$. Results of the present study are in keeping with these previous results in terms of the direction of changes, although previous work has generally found a greater magnitude of difference between the two behavioral states. Studies that have evaluated CBF have primarily performed sequential flow determinations within the same day $(5,21)$. In the present study, LV/REM and HV/NREM behavioral state blood flow determinations were made on separate days, most likely contributing to greater biologic variability between the two behavioral state blood flow measures, thus resulting in no statistically significant effect to the brain as a whole. Previous work suggests that blood flow to the brain may differ by $5 \%$ between two HV electrocortical activity epochs separated by one LV electrocortical activity epoch (29), and this biologic/methodologic variation may account for the lack of difference observed in this study. This protocol illustrates that blood flow was significantly greater during LV/REM than HV/NREM behavioral state to the subcortex and brainstem, in keeping with previous studies that found similar differences in blood flow $(25,29)$. Cerebral oxygen delivery controls for any changes in blood oxygenation levels and tended to be greater in the brain during LV/REM than HV/NREM behavioral state, in keeping with previous studies $(5,21)$. It should be noted that in this study, all blood flow determinations were made at a similar time of day to prevent any influence of diurnal rhythm in CBF (30).

Regional $\mathrm{CBF}$ is coupled to local metabolic requirements (31) and thus neuronal activity (32). Cholinergic neurotransmission plays an important role in the regulation of $\mathrm{CBF}$ as a result of the vasodilative effects of acetylcholine. Physiologic stimulation of neurons leads to acetylcholine release, and this local acetylcholine release in turn increases local CBF (32). Muscarinic acetylcholine receptors are found on vascular and astroglial components of human brain tissue and play a role in the regulation of cortical perfusion (33). The cholinergic agents used in the present study may have acted directly on blood vessels altering $\mathrm{CBF}$ independent of fetal behavioral state. Carbachol injection in the basal forebrain causes an increase in acetylcholine in the parietal cortex (14), suggesting that although our drug injection was into the cerebrospinal fluid bathing the pons and medulla, we may have influenced brain areas beyond this region. Nitric oxide (34) and oxygen diffusion limitation in the brain (7) also play a role in mediating CBF changes observed during different sleep states. The cholinergic agents used in this study may have acted indirectly 
through the release of nitric oxide. Nitric oxide synthase inhibition in the newborn lamb prevents the increase in blood flow normally observed in the sagittal sinus during REM sleep (34).

CMR determines CBF and oxygen delivery. Therefore, if CMR increases, then $\mathrm{CBF}$ and oxygen delivery will also increase; however, the opposite is not necessarily true. Microinjection of carbachol into the substantia innominata of anesthetized rats caused an increase in CBF to many ipsilateral regions; however, cerebral glucose use remained unchanged in all areas except the substantia innominata and the amygdala (14). CMR of glucose is not changed with i.v. physostigmine infusion, a cholinesterase inhibitor, when compared with vehicle in rats without controlling for sleep state $(35,36)$, suggesting that neuronal activity was not affected by physostigmine. In the present study, CBF during carbachol-induced LV/REM behavioral activity was generally greater than during all other behavioral states, including spontaneous LV/REM behavioral state, whereas oxygen delivery was generally lower than that observed during spontaneous LV/REM behavioral state. This increased CBF suggests that CMR during carbachol-induced LV/REM behavioral state may have been elevated. The pairing of the magnitude of $\mathrm{CBF}$ and oxygen delivery suggests that CMR is similar during spontaneous and carbachol-induced LV/REM behavioral state.

Intravenous scopolamine infusion and its effects on CBF and CMR of glucose have been investigated in both rat and human paradigms of learning, memory, and aging (37) but not in relation to sleep-wake patterns. The results of the present study showed that CBF during scopolamine-induced HV/NREM behavioral state was lower than that during the other behavioral states, confirming previous studies in both cats and humans $(32,37,38)$. This is not likely a direct effect of scopolamine, as it has no known vasoactive properties (32). Animal studies have found no change in cerebral glucose uptake (32,35-37), suggesting that scopolamine may reduce $\mathrm{CBF}$ without affecting neuronal activity in the cat and the rat during anesthesia (32). Human studies of CMR of glucose found an increase in $\mathrm{CMR}_{\text {glu }}$ with scopolamine infusion (35). The results of the present study show that oxygen delivery was lower during scopolamine-induced HV/NREM behavioral activity compared with the other three behavioral states. Although lower, the magnitude of $\mathrm{CBF}$ and oxygen delivery during scopolamine-induced HV/NREM was most similar to that during spontaneous HV/NREM behavioral state. These results suggest that CMR may be lower during scopolamine-induced HV/ NREM behavioral state compared with the other behavioral states investigated in this study with similarity to spontaneous HV/NREM behavioral state.

\section{CONCLUSION}

In summary, the present study suggests that CBF observed during cholinergically induced behavioral states is in fact similar to that observed during spontaneous behavioral states in the sheep fetus. Both spontaneous and carbachol-induced LV/ REM behavioral state are associated with greater CBF and oxygen delivery when compared with both spontaneous and scopolamine-induced HV/NREM behavioral state. The function of sleep remains elusive, and this pursuit is hampered by the short epochs of each sleep state and their cyclical nature. This study provides evidence that fetal behavioral states can be chronically manipulated, allowing study of the metabolic consequences during the brain's growth and developmental stages in precocious mammals in utero. Previous work in rats, altricial mammals, show that inhibiting REM sleep during the major growth and developmental period of the brain results in increased anxiety, reduced sexual activity, disturbed sleep, and a reduction in cerebral cortex and brainstem size in adulthood (39). Pharmacologic induction of fetal behavioral state in sheep coupled with our ability to continuously monitor CBF (40-42) may aid in determining the role of LV/REM and HV/NREM behavioral states on the growth and development of the fetal brain during late gestation, a period of both rapid brain growth and development.

Acknowledgments. We thank the Canadian Institutes of Health Research for grants supporting this work. We also thank Drs. A. Bocking, R. Gagnon, J. Vazquez, and I.C. McMillen for ongoing interest in this work.

\section{REFERENCES}

1. Szeto HH, Vo TD, Dwyer G, Dogramajian ME, Cox MJ, Senger G 1985 The ontogeny of fetal lamb electrocortical activity: a power spectral analysis. Am J Obstet Gynecol 153:462-466

2. Clapp JF 3rd, Szeto HH, Abrams R, Larrow R, Mann LI 1980 Physiologic variability and fetal electrocortical activity. Am J Obstet Gynecol 136:1045-1050

3. Parkes MJ 1992 Fetal behavioural states: sleep and wakefulness? Q J Exp Psychol B 44:231-244

4. Richardson BS, Caetano H, Homan J, Carmichael L 1994 Regional brain blood flow in the ovine fetus during transition to the low-voltage electrocortical state. Brain Res Dev Brain Res 81:10-16

5. Richardson BS, Patrick JE, Abduljabbar H 1985 Cerebral oxidative metabolism in the fetal lamb: relationship to electrocortical state. Am J Obstet Gynecol 153:426-431

6. Madsen PL, Schmidt JF, Wildschiodtz G, Friberg L, Holm S, Vorstrup S, Lassen NA 1991 Cerebral $\mathrm{O}_{2}$ metabolism and cerebral blood flow in humans during deep and rapid-eye-movement sleep. J Appl Physiol 70:2597-2601

7. Lenzi P, Zoccoli G, Walker AM, Franzini C 2000 Cerebral circulation in REM sleep: is oxygen a main regulating factor? Sleep Res Online 3:77-85

8. Braun AR, Balkin TJ, Wesenten NJ, Carson RE, Varga M, Baldwin P, Selbie S, Belenky G, Herscovitch P 1997 Regional cerebral blood flow throughout the sleepwake cycle. An H2(15)O PET study. Brain 120:1173-1197

9. Gnadt JW, Pegram GV 1986 Cholinergic brainstem mechanisms of REM sleep in the rat. Brain Res 384:29-41

10. Zoltoski RK, Velazquez-Moctezuma J, Shiromani PJ, Gillin JC 1993 The relative effects of selective M1 muscarinic antagonists on rapid eye movement sleep. Brain Res 608:186-190

11. Bissonnette JM, Hohimer AR, Knopp SJ 1994 A cholinergic mechanism involved in fetal breathing during the high voltage ECoG state. Respir Physiol 96:151-162

12. Morrison JL, Carmichael L, Homan J, Richardson BS 1997 The effects of 'sleep promoting agents' on behavioural state in the ovine fetus. Brain Res Dev Brain Res 103:1-8

13. Ouchi Y, Fukuyama H, Ogawa M, Yamauchi H, Kimura J, Magata Y, Yonekura Y, Konishi J 1996 Cholinergic projection from the basal forebrain and cerebral glucose metabolism in rats: a dynamic PET study. J Cereb Blood Flow Metab 16:34-41

14. Barbelivien A, Bertrand N, Besret L, Beley A, MacKenzie ET, Dauphin F 1999 Neurochemical stimulation of the rat substantia innominata increases cerebral blood flow (but not glucose use) through the parallel activation of cholinergic and noncholinergic pathways. Brain Res 840:115-124

15. Richardson BS, Carmichael L, Homan J, Patrick JE 1992 Electrocortical activity, electroocular activity, and breathing movements in fetal sheep with prolonged and graded hypoxemia. Am J Obstet Gynecol 167:553-558

16. Bissonnette JM, Hohimer AR, Richardson BS 1981 Ventriculocisternal cerebrospinal perfusion in unanesthetized fetal lambs. J Appl Physiol 50:880-883

17. Joseph SA, Walker DW 1993 Effects of intracisternal monoamines on breathing movements in fetal sheep. Am J Physiol 264:R1139-R1149

18. Buckberg GD, Luck JC, Payne DB, Hoffman JI, Archie JP, Fixler DE 1971 Some sources of error in measuring regional blood flow with radioactive microspheres. J Appl Physiol 31:598-604

19. Heymann MA, Payne BD, Hoffman JI, Rudolph AM 1977 Blood flow measurements with radionuclide-labeled particles. Prog Cardiovasc Dis 20:55-79 
20. Makowski EL, Schneider JM, Tsoulos NG, Colwill JR, Battaglia FC, Meschia G 1972 Cerebral blood flow, oxygen consumption, and glucose utilization of fetal lambs in utero. Am J Obstet Gynecol 114:292-303

21. Richardson BS, Carmichael L, Homan J, Gagnon R 1989 Cerebral oxidative metabolism in lambs during perinatal period: relationship to electrocortical state. Am J Physiol 257:R1251-R1257

22. Bocking AD, Gagnon R, Milne KM, White SE 1988 Behavioral activity during prolonged hypoxemia in fetal sheep. J Appl Physiol 65:2420-2426

23. Matsuda Y, Patrick J, Carmichael L, Fraher L, Richardson B 1994 Recovery of the ovine fetus from sustained hypoxia: effects on endocrine, cardiovascular, and biophysical activity. Am J Obstet Gynecol 170:1433-1441

24. Ioffe S, Jansen AH, Russell BJ, Chernick V 1980 Sleep, wakefulness and the monosynaptic reflex in fetal and newborn lambs. Pflugers Arch 388:149-157

25. Jensen A, Bamford OS, Dawes GS, Hofmeyr G, Parkes MJ 1986 Changes in organ blood flow between high and low voltage electrocortical activity in fetal sheep. J Dev Physiol 8:187-194

26. Rurak DW, Gruber NC 1983 Increased oxygen consumption associated with breathing activity in fetal lambs. J Appl Physiol 54:701-707

27. Gardner DS, Fletcher AJ, Bloomfield MR, Fowden AL, Giussani DA 2002 Effects of prevailing hypoxaemia, acidaemia or hypoglycaemia upon the cardiovascular, endocrine and metabolic responses to acute hypoxaemia in the ovine fetus. J Physio 540:351-366

28. Morrison JL 1996 The Effects of 'Sleep Altering' Pharmacological Agents on Ovine Fetal Behavioural State. Department of Physiology, University of Western Ontario, London, p 114

29. Rankin JH, Landauer M, Tian Q, Phernetton TM 1987 Ovine fetal electrocortical activity and regional cerebral blood flow. J Dev Physiol 9:537-542

30. Endo Y, Jinnai K, Endo M, Fujita K, Kimura F 1990 Diurnal variation of cerebral blood flow in rat hippocampus. Stroke 21:1464-1469

31. Sokoloff L 1981 Relationships among local functional activity, energy metabolism, and blood flow in the central nervous system. Fed Proc 40:2311-2316
32. Ogawa M, Magata Y, Ouchi Y, Fukuyama H, Yamauchi H, Kimura J, Yonekura Y, Konishi J 1994 Scopolamine abolishes cerebral blood flow response to somatosensory stimulation in anesthetized cats: PET study. Brain Res 650:249-252

33. Elhusseiny A, Cohen Z, Olivier A, Stanimirovic DB, Hamel E 1999 Functional acetylcholine muscarinic receptor subtypes in human brain microcirculation: identification and cellular localization. J Cereb Blood Flow Metab 19:794-802

34. Zoccoli G, Grant DA, Wild J, Walker AM 2001 Nitric oxide inhibition abolishes sleep-wake differences in cerebral circulation. Am J Physiol 280:H2598-H2606

35. Blin J, Ray CA, Piercey MF, Bartko JJ, Mouradian MM, Chase TN 1994 Comparison of cholinergic drug effects on regional brain glucose consumption in rats and humans by means of autoradiography and position emission tomography. Brain Res 635:196202

36. Ray CA, Blin J, Chase TN, Piercey MF 1992 Effects of cholinergic agonists on regional brain energy metabolism in the scopolamine-treated rat. Neuropharmacology 31:1193-1199

37. Gitelman DR, Prohovnik I 1992 Muscarinic and nicotinic contributions to cognitive function and cortical blood flow. Neurobiol Aging 13:313-318

38. Cohen RM, Gross M, Semple WE, Nordahl TE, Sunderland T 1994 The metabolic brain pattern of young subjects given scopolamine. Exp Brain Res 100:133-143

39. Mirmiran M, Maas YG, Ariagno RL 2003 Development of fetal and neonatal sleep and circadian rhythms. Sleep Med Rev 7:321-334

40. Czikk MJ, Green LR, Kawagoe Y, McDonald TJ, Hill DJ, Richardson BS 2001 Intermittent umbilical cord occlusion in the ovine fetus: effects on blood glucose, insulin, and glucagon and on pancreatic development. J Soc Gynecol Investig 8:191-197

41. Grant DA, Franzini C, Wild J, Walker AM 1995 Continuous measurement of blood flow in the superior sagittal sinus of the lamb. Am J Physiol 269:R274-R279

42. Czikk MJ, Totten S, Homan JH, White SE, Richardson BS 2001 Sagittal sinus blood flow in the ovine fetus as a continuous measure of cerebral blood flow: relationship to behavioural state activity. Brain Res Dev Brain Res 131:103-111 